salient features of its eruption were recorded by an eyewitness in the sixteenth century. The others probably date from prehistoric times; otherwise, such a marvel as an extensive eruption could not have escaped mention by some Greek or Roman author. In the table, the younger volcanic structures are arranged above those which are considered to be older, and lines connect those between which it is thought that some evidence of relative age can be detected.

In my recent paper I have shown that almost all the hills of the Phlegræan Fields are either the entire walls of volcanic craters or of portions of walls of volcanic craters which have been to a greater or less extent washed away by the action of rain or the sea, or have been partially destroyed or buried by more recent volcanic eruptions. Secondly, these volcanic craters are distributed over a crescentic area round the Bay of Pozzuoli; the more recent ones are situated closer to the shore of the bay than the older ones, indicating a gradual march of volcanic vents along lines radiating towards the centre of that bay. In other words, the general effect of volcanic activity has been the accumulation of new land around the bay of Pozzuoli. Inasmuch as water seems to be a necessity for a volcanic eruption, this progression of the volcanoes seawards may stand in some relation to the channels by which water has obtained access to the fires below.

Thirdly, wherever crater rings of a larger and smaller diameter overlap, we never find a larger ring superimposed on a smaller one. The smaller ring is always superimposed on the larger. The conclusion to be drawn is, that the volcanic activity of the region has been decreasing in intensity. The same proposition is proved for a single locality by the Campana series of craters.

As it is impossible to make all the above-mentioned points clear without a suitable map, I would draw the attention of the interested reader to the surveys of the region published by the Istituto Geografico Militare, and to the contoured map published in the Geographical Journal for October I 897 .

R. T. GÜNTHER.

\section{THE PRESENT APPEARANCE OF JUPITER}

$\mathrm{T} \mathrm{T}$ may be interesting, now that the planet Jupiter is very favourably situated, to call attention to a few of the more conspicuous features which diversify its surface. Many of these objects will be sure to have come under the repeated observation of all those observers who have been habitually examining the planet in their telescopes.

It is fortunate that at the present time there are a large number of conspicuous markings on the planet. These are situated in different latitudes, and will allow some excellent redeterminations to be made of the velocities of the various longitudinal currents.

There are a great many dark and bright spots visible near the equator, on the north side of the southern equatorial belt. Some of these at the date of writing (April 18) are placed in the following longitudes, which are computed on the basis of System $\mathbf{I}$. (daily rate $877^{\circ} 90$ $=9 \mathrm{~h}$. 5om. 3os.) in Mr. Crommelin's ephemerides in Monthly Notices for January 1898.

\begin{tabular}{ccccrcccc} 
& \multicolumn{1}{c}{ Bright spors. } & \multicolumn{3}{c}{ Dark spots. } \\
Long. &.. & $\ldots$ & $\ldots$ & 80 & $\ldots$ & $\ldots$ & $\ldots$ & 7 I \\
, & $\ldots$ & $\ldots$ & $\ldots$ & 146 & $\ldots$ & $\ldots$ & $\ldots$ & 94 \\
, & $\ldots$ & $\ldots$ & $\ldots$ & 209 & $\ldots$ & $\ldots$ & $\ldots$ & I 6 \\
, & $\ldots$ & $\ldots$ & $\ldots$ & 238 & $\ldots$ & $\ldots$ & $\ldots$ & 127 \\
, & $\ldots$ & $\ldots$ & $\ldots$ & 270 & $\ldots$ & $\ldots$ & $\ldots$ & 155 \\
, & $\ldots$ & $\ldots$ & $\ldots$ & 349 & $\ldots$ & $\ldots$ & $\ldots$ & 216 \\
& & & & & & & & 279 \\
& & & & & & & & 319
\end{tabular}

No. 1486 , VOL. 57$]$
These markings are moving at approximately the same rate as the zero meridian System 1., but I find that in several cases there is a disposition of the spots to decrease in longitude ; hence I believe that their rotation periods will prove to be slightly less than 9 h. $50 \mathrm{~m} .30 \mathrm{~s}$. The bright spots exhibit great variations in their appearance, and some irregularities of motion. A spot which is conspicuously brilliant on one night may, a few evenings later, have declined so much that it can scarcely be discerned.

The great red spot is still visible, and its present longitude is about $24^{\circ}$, so that it follows the zero meridian of System II. in the ephemerides by about forty minutes. The spot has the aspect of a faint dusky ellipse with a light interior, and it is connected on its south side with a grey belt. The recent motion of the spot corresponds with a period of $9 \mathrm{~h} .55 \mathrm{~m} .41 \cdot 5 \mathrm{~s}$., and it may be expected to drop further behind its computed place unless an acceleration of motion should set in. Comparing an observation of the spot which I obtained on April 17, 1898, I $2 \mathrm{~h}$. $5 \mathrm{~m}$., with one of the earliest by Mr. Dennett, of Southampton, on July 27,1878 , I find that 17,414 rotations were performed in the interim of 7203 days, and that the mean period of rotation was

$$
\text { 9h. } 55 \mathrm{~m} .39^{\circ} 4 \mathrm{~s} \text {. }
$$

This value is identical with that found by Prof. Hough from 14,505 rotations between $1879-96$.

In July 1898 the spot will have been visible during twenty years, and under careful observation at each opposition of the planet. Whether this object is identical with other elliptical or reddish spots seen at various times in the same latitude by Dawes (1857), Huggins (1858-59), Gledhill (I869-70), Lord Rosse (1873), Copeland (I873), Russell (1876), and others, must remain an open question. It appears highly probable that the spot was the same as that observed by Russell in the summer of 1876 , but there is an absence of connecting observations in 1877 . And the identity of two or more markings cannot be absolutely proved by their longitudes when a fairly long interval has intervened between the observations, because the proper motions of the object are variable, and introduce great differences of longitude not always in the same direction. The retarded westerly drift of the red spot has caused it to lose more than 900 degrees of longitude relatively to its place in 1878 , so that the spot has really been displaced to the extent of about two and a half circumferences of the planet.

From my own observations of the spot since 1880 , I have obtained the following rotation periods for a certain interval during each apparition :-

\begin{tabular}{|c|c|c|c|c|c|c|c|}
\hline \multicolumn{4}{|c|}{ Limiting observations. } & \multicolumn{3}{|c|}{ Rotations. } & Period. \\
\hline 880 & Sep & $27-188 \mathrm{I} \mathrm{Ma}$ & 17 & $\cdots$ & 413 & 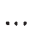 & $5535^{\circ} 6$ \\
\hline 88 & July & 8-I882 March & 30 & .. & 640 & $\cdots$ & $3^{8 \cdot 2}$ \\
\hline 88 & July & 29-1883 May & 4 & $\cdots$ & 674 & $\ldots$ & $95539^{\circ}$ \\
\hline 383 & Aug. & 23-I884 June & 12 & $\ldots$ & 710 &. & $39^{\circ}$ \\
\hline 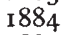 & Sept. & $2 \mathrm{I} \sim \mathrm{I} 885$ July & 8 & $\ldots$ & 700 & $\ldots$ & \\
\hline 88 & Oct. & $24-1886$ July & 24 & $\cdots$ & 659 & $\cdots$ & \\
\hline 80 & Nov. & 23-1887 Aug. & 2 & .. & 609 & ... & 9 \\
\hline 88 & Feb. & I2-I 888 Aug. & 22 & $\cdots$ & 462 & $\ldots$ & 9 \\
\hline 880 & May & 9 Nov. & 26 & $\cdots$ & 439 & $\cdots$ & 95 \\
\hline 90 & May & o Nov. & 25 & $\ldots$ & 451 & $\ldots$ & \\
\hline 89 & Aug. & 7-1892 Feb. & 2 & $\ldots$ & 432 & $\ldots$ & 9 \\
\hline 30 & Aug. & I 5-I893 March & 8 & .. & 495 & ... & 9 \\
\hline & Aug. & 9-1894 March & 24 & $\cdots$ & 548 & $\cdots$ & $I$ \\
\hline & ov. & 25-1895 May & Io & $\ldots$ & 401 & ... & \\
\hline & g. & $6 \mathrm{Feb}$ & 22 & $\cdots$ & 439 & $\cdots$ & \\
\hline & 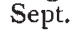 & 27-1897 April & 25 & & $5^{14}$ & $\ldots$ & $3540^{\circ}$ \\
\hline
\end{tabular}

The red spot has been falling behind the zero meridian during the last six or seven years, but at a very slow rate, the mean annual retardation being only about six minutes.

There are a number of dark, elongated spots or short belts placed in various regions of the planet. They are 
conspicuous objects on nights when the seeing is good, and the times of their passages across the planet's central meridian are easily secured. The following are the longitudes of a few of these formations as computed from System II. of the ephemerides :-

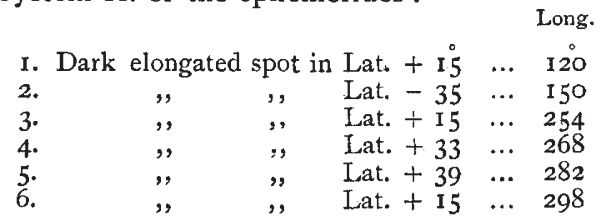

Nos. I, 3 and 6 are placed in the bright tropical zone, and immediately outlying the northern edge of the north equatorial belt. They are moving somewhat faster than the red spot, as their longitude appears to be decreasing at the rate of about $10^{\circ}$ per month. Nos. 4 and 5 in the north temperate zone are moving at approximately the same velocity as the red spot.

There are some well-defined irregularities in the north side of the northern equatorial belt, which exhibits both white and dark spots. Their motion is evidently controlled by a rapid current similarly to that of the white and dark equatorial spots, but not, perhaps, quite so extreme.

Bright spots appear in the zone south of the red spot, and several of these are being attentively followed with the object of determining their periods.

On the whole the planet's appearance is now singularly replete with detail, and will compare favourably with that exhibited at any previous opposition. The great red spot has, it is true, long since lost the intense brick-red colour it displayed in the years $1878-81$; nor have we now the exceedingly brilliant white equatorial spots of the period named. But appearances are now visible on the disc which were absent then, and among the most interesting of these are the elongated dark spots situated just outside the margin of the north equatorial belt.

Though past observation has fully demonstrated the proper motions of the different markings and the decreasing velocity of several of them, it is highly important that the rate of the various currents should be redetermined every year. The character and number of the spots found in them should also be recorded, and measures made to determine the latitudes of the belts. Pursued through a long series of years, such data might ultimately give us the proof of periodical variations in the character and number of the spots, and possibly also in their rates of motion.

W. F. DENNIN

\section{THE LONDON UNIVERSITY BILL.}

$T H E$ friends of education and many friends of the Government are disappointed at the postponement of the second reading of this Bill in the House of Commons. The cynics are saying that aristocratic Government and University representation are either jointly or severally responsible for this recurrent paralysis in the treatment of a question of the greatest importance to the greatest city of the world.

NATURE is not a political organ, and these points need not therefore occupy us ; we can only express regret that the way in which all matters connected with science and education are handled in this country is so vastly different from that meted out to them in France or Germany. The Times writes as follows:

It is no longer denied in any quarter that the absence of a teaching University in the capital of the British Empire and the greatest city in the world is an anomaly and almost a scandal. The alternative which commends itself to Mr. Moulton and the anti-reform party is that a new teaching University should be set up alongside of the present examining University, but this scheme has been rejected by the vast majority of intelligent men who have taken even the slightest pains to look into the sub. ject. What the Government desire-in accordance, we believe, with the immense preponderance of authority on this question - is to connect a teaching University, under which degrees will be given as the hall-mark of a systematic intellectual training, with the existing system of examination pure and simple. The latter, it is pointed out, is left entirely untouched, though there is a strong and growing conviction that it never can be, even in part, a true development of the highest education, but must tend, more and more, to pass under the dominion of the crammer. But the preservation of the existing method of giving degrees makes it imperative, if the teaching work of the University is to be a reality and not a sham, that there should be a double system of examinations, the one for "internal" and the other for " external" students. The Bill provides, necessarily and inevitally, for this distinction, but the most careful securities are adopted that no unfair advantage shall be given to the former class, and, especially, that the examination of students by the teachers who have trained them shall be supplemented and checked by the admission of an independent element. It would seem to be forgotten that the medical degrees of the London University, which undoubtedly stand highest in public estimation and of which the standard is rigorously high, are granted on the reports of examiners many of whom are teachers in the medical schools. The cry for identity of examinational tests is irrelevant and in-

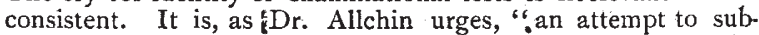
ordinate the examinations to the requirements of those who have neither been trained nor educated in the fullest sense of the word." This is the very essence of the bondage from which for many years past the higher education in London has been struggling, under the guidance of such men as Huxley, to escape, and from which deliverance is now in sight, if Ministers will only have the courage of their opinions and be true to their pledges.

Whether the paralysis comes from want of knowledge or want of courage, it is very clear that there is at the present a great gap in our ađministrative machinery, and one which a Scientific and Educational Committee of the Privy Council might easily fill if the right men were appointed to it.

\section{NOTES}

THE death is announced of Prof. Aimé Girard, member of the Section of Rural Economy of the Paris Academy of Sciences. Referring to the deceased investigator at the meeting of the Academy on April 12, M. Th. Schlœesing remarked: M. Aimé Girard was the highest authority on chemical and agricultural industries in the Academy. After some valuable scientific work he was nominated professor of industrial chemistry at the Conservatoire des Arts et Métiers, in succession to Payen. His teaching revealed the dominating object of his efforts. Affable and cheerful, loyal and entirely disinterested, he possessed all the attributes required to gain the confidence of manufacturers. The producers whose places he visited, in France and in other countries, became and remained his friends; they gave to him a large amount of information which he used to enrich his attractive lectures, and in return M. Girard offered them advice suggested by his experience and his own investigations. In a few years his masterly researches on vegetable fibres, wheat, farinas, sugars and woods had made him the first authority upon these matters, and he was frequently consulted by the Government on subjects concerning the great industries of paper, alcohol, sugar, flour, and bakery. The study of these products led to inquiries as to crops. In this new direction M. Girard rendered valuable services, and, after his researches on the cultivation of sugar-beet and the improvement of the potato, he obtained among agriculturists the same position and the same sympathies which he enjoyed in the industrial world. Though weakened in recent years by illness, and saddened by repeated troubles, he nevertheless continued his work. He died while occupied in applying to wheat of various. 